\title{
Multiple Sclerosis Presenting as a Delirium: A Case Report
}

\author{
Nastaran Mahboobi ${ }^{a} \quad$ Silke Nolden-Hoverath ${ }^{a}$ Olaf Rieker $^{b} \quad$ Hartmut Bauer $^{a}$ \\ Departments of a Neurology and ${ }^{\mathrm{b}}$ Radiology, Marien Hospital Euskirchen, Teaching Hospital of Bonn University, \\ Euskirchen, Germany
}

\section{Key Words}

Multiple sclerosis · Delirium · Plasmapheresis

\begin{abstract}
Objective: To report a case of multiple sclerosis (MS) with delirium as the first presentation. Clinical Presentation and Intervention: A 34-year-old female was referred to our department with an acute onset of drowsiness, withdrawal from routine activities and aggression, followed by neurologic deficits after a couple of days. Clinical and radiographic examinations were performed, leading to the initial diagnosis of MS. A vast range of differential diagnoses was excluded to confirm the diagnosis of MS. Conclusion: Neurological examination and appropriate imaging enabled the diagnosis of MS with delirium in this patient followed by the appropriate treatment.

(c) 2015 S. Karger AG, Basel
\end{abstract}

\section{Introduction}

Discriminating the various types of demyelinating diseases, described as a range of inflammatory demyelinating disorders (IDDs), such as acute disseminated encephalomyelitis, multiple sclerosis (MS) and neuromyelitis optica, is not always immediately possible [1]. While

\begin{tabular}{ll}
\hline KARGER 125/s & $\begin{array}{l}\text { ( } 2015 \text { S. Karger AG, Basel } \\
1011-7571 / 15 / 0244-0388 \$ 39.50 / 0 \quad \text { Karger }\end{array}$ \\
E-Mail karger@karger.com & $\begin{array}{l}\text { This is an Open Access article licensed under the terms of the } \\
\text { www.karger.com/mpp }\end{array}$ \\
& $\begin{array}{l}\text { Creative Commons Attribution-NonCommercial 3.0 Un- } \\
\text { ported license (CC BY-NC) (www.karger.com/OA-license), } \\
\text { applicable to the online version of the article only. Distribu- } \\
\text { tion permitted for non-commercial purposes only. }\end{array}$
\end{tabular}

acute disseminated encephalomyelitis is a usually monophasic vital form of IDDs often following a viral disease or vaccination and more common in children [2], neuromyelitis optica preferentially affects optic nerves and the spinal cord, targeting the channel protein aquaporin- 4 [3]. MS as the most common IDD often has a chronically progressive process leading to different disabilities [1]. On the other hand, IDDs sometimes mimic the clinical process of infectious diseases such as herpes encephalitis or bacterial meningitis $[4,5]$. Since the definite diagnosis determines the therapeutic consequences, all clinical and paraclinical aspects of such cases should be considered essential in order to make an accurate diagnosis without wasting time [6].

In this case report, a young woman presenting with a sudden onset of delirium as the first presentation of MS, gradually followed by neurologic deficits, is described. To our knowledge, this is the first report of delirium as the initial sign of MS till now.

\section{Case Report}

A 34-year-old, previously healthy female was admitted to our hospital in February 2012 with a recent onset of progressive psychosyndrome, bilateral hand numbness and dysarthria. Reviewing of her medical history revealed a previous admission to another hospital with acute onset of psychiatric symptoms including

Dr. med. Hartmut Bauer

Neurology Department, Marien Hospital Euskirchen

Teaching Hospital of Bonn University, Gottfried-Disse-Straße 40

DE-53879 Euskirchen (Germany)

E-Mail hartmut.bauer@marien-hospital.com 
Fig. 1. a The first MRI before the therapy. b A new lesion in the follow-up MRI after methylprednisolone therapy (arrow). c Follow-up MRI after 5 cycles of plasmapheresis.
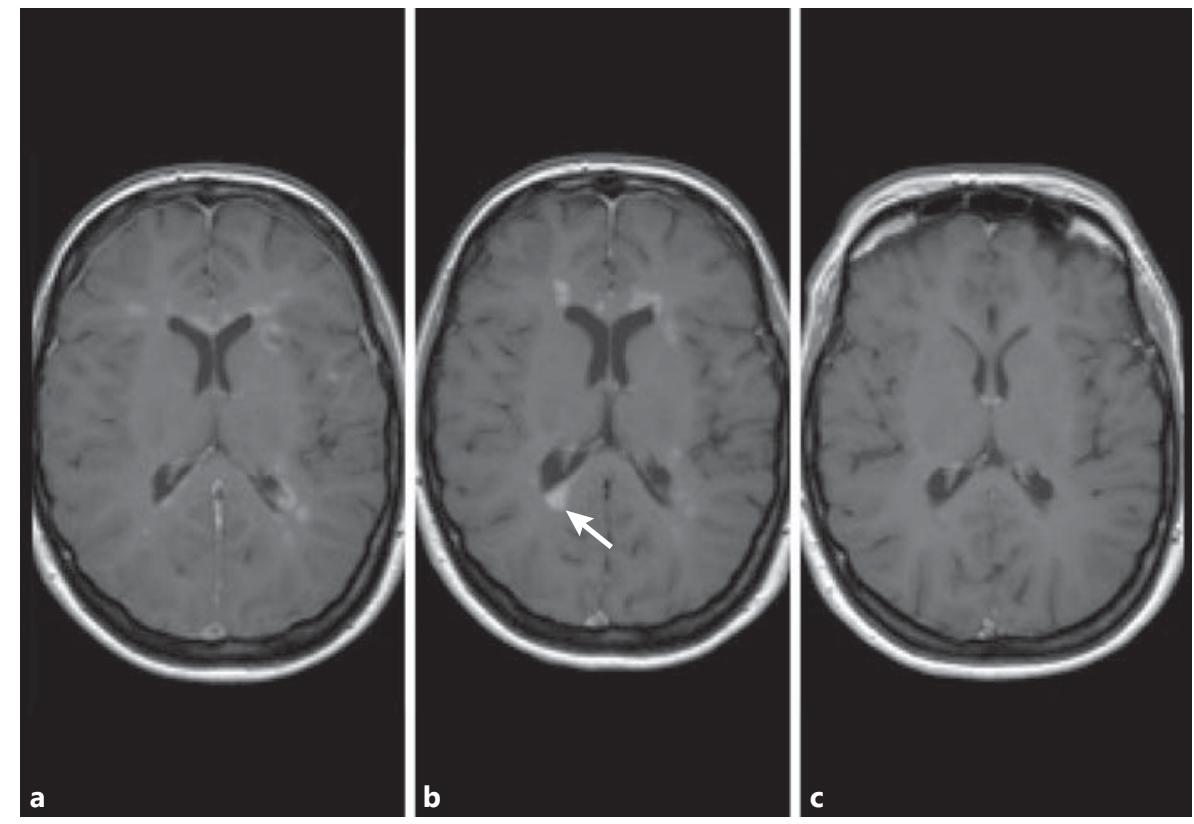

drowsiness, loss of energy and aggression, a noncomplicated normal vaginal delivery 4 weeks prior this admission, mild hypothyroidism and gestational hypertension. The patient denied the use of cigarettes, alcohol or illicit drug abuse. She had a positive family history for colon and bronchial cancer in her parents.

The patient was admitted with a diagnosis of progressive delirium with an unclear underlying etiology. Upon admission, the vital signs were within normal ranges. An extensive neurological examination was performed, which revealed dysarthria, sustained gaze-evoked and vertical nystagmus, hypoesthesia at the periumbilical level with both the upper and the lower extremities more prominent on the left side, spinal ataxia and no abdominal skin reflex. There were no signs of nuchal rigidity, no Kernig's and Brudzinski's signs or musculoskeletal weakness in the physical examination.

The psychopathological examination showed drowsiness, slower formal thought, reduced incitement and mnestic deficiency. The aggression was controlled after starting with antipsychotics (haloperidol $5 \mathrm{mg} /$ day). The electroencephalogram showed a slow activity of $7 \mathrm{~Hz}$.

The symptoms were suggestive of a cognition-involving disorder, while the physical findings suggested a central lesion. A 1.5-T magnetic resonance imaging (MRI) of the brain revealed multiple periventricular hyperintensities in FLAIR, with hypointensities in $\mathrm{T}_{1}$, a sever lesion load in $\mathrm{T}_{2} /$ FLAIR images, black holes in $\mathrm{T}_{1}$ and multiple fresh inflammatory foci after gadolinium enhancement (fig. 1a). Subsequently, an MRI of the cervical spine was obtained showing a $16 \times 3$-mm central lesion between the $\mathrm{C}_{4}$ and $\mathrm{C}_{5}$ vertebral bodies.

The neurophysiological examination showed a pathologic visually-evoked potential by demyelination of the optic nerve and a pathologic transcranial magnet stimulation by pyramid lesions. The sensible-evoked potentials were normal.

In a further workup, the patient's blood test was negative for human immunodeficiency virus, hepatitis $B$ virus, hepatitis $C$ vi- rus, syphilis, antinuclear antibody, double-strand DNA antibody, phospholipid antibody, cardiolipin antibody, antineutrophil cytoplasmic antibody, perinuclear antineutrophil cytoplasmic antibody, erythrocyte sedimentation rate, C-reactive protein, aquaporin-4 antibody and NMDA receptor antibody. No evidence of a paraneoplastic syndrome could be detected.

A primary cerebrospinal fluid (CSF) analysis indicated normal opening pressure, clear CSF, a 95\% lymphocytic pleocytosis of 190 cells/ $\mu \mathrm{l}$, a total protein level of $112 \mathrm{mg} / \mathrm{dl}$, lactate of $2.1 \mathrm{mmol} / \mathrm{l}$, glucose of $68 \mathrm{mg} / \mathrm{dl}$ and a red blood cell number of 2 . Furthermore, oligoclonal bands were positive and a positive measles-rubellavaricella zoster reaction (highly sensitive for MS) was verified. The $\mathrm{CSF} /$ serum glucose index was normal. The pleocytosis in the CSF led to the immediate administration of an antibiotic and antiviral therapy. As a polymerase chain reaction and an enzyme-linked immunosorbent assay of CSF were negative for any viral or bacterial infection, the diagnosis of herpes encephalitis, lyme and other vi$\mathrm{ral} / \mathrm{bacterial}$ encephalitis were ruled out.

Based on the clinical symptoms and MRI findings, the therapy was started with methylprednisolone $2 \mathrm{~g}$ for 5 days, with a proton pump inhibitor and with an antithrombosis injection. Antiviral treatment and antibiotics were discontinued. The symptoms improved after the treatment course, but new lesions were detected in the follow-up MRI (fig. 1b). Finally, based on McDonald criteria, the patient was diagnosed with MS. Consequently, plasmapheresis was started which led to the subsiding of both the symptoms and the MRI lesions after 5 well-tolerated apheresis cycles with a median exchange volume of 3 liters (range 2.5-3.5) (fig. 1c). Logically, antipsychotic therapy was omitted from the therapy plan.

The CSF analysis after the therapy showed a pleocytosis of 30 cells/ $\mu$ l, including $94 \%$ lymphocytes, $3 \%$ monocytes and $1 \%$ other cells and a normal protein level of $43 \mathrm{mg} / \mathrm{dl}$. Our patient was approximately complaint free and was discharged with an expanded disability status scale of 1.5. Due to the highly active process of the 
MS, an escalation therapy with natalizumab was started for 2 weeks after the discharge. Her symptoms were controlled with regular natalizumab therapy with no episode of flare-up since 28 months. John Cunningham virus antibody was negative.

\section{Discussion}

In this study, a rare first presentation of MS has been reported, a case of a young, previously healthy woman with a sudden onset of delirium.

MS symptoms typically start with optic nerve, spinal cord or brainstem lesions with cognitive and mood disorders as late presentations [7]. However, there are a few reports of psychiatric disorders in MS patients. Recently, Tapos et al. [8] reported a rare presentation of MS in a 16 -year-old male who was initially diagnosed with schizoaffective disorder. A brain MRI was performed on him after developing neurologic deficits, which confirmed the MS diagnosis [7]. Additionally, Yadav and Zigmond [9] reported a known case of MS in 2010, presenting with psychosis secondary to left temporal lesions. In a review of psychotic features of MS, Kosmidis et al. [10] showed that despite unclear etiology, left temporal lesions and corticosteroid therapy might play a role in the psychopathology of psychosis in MS.

It was not easy to make a unifying MS diagnosis in our case, since delirium is an uncommon first presentation of MS. Furthermore, The CSF showed a pleocytosis of 190 cells/ $\mu \mathrm{l}$, which is much higher than the expected CSF pleocytosis of 100 cells/ $\mu$ l described in the literature. The high protein level of $112 \mathrm{mg} / \mathrm{dl}$, which is not expected in MS patients, made the diagnosis more difficult as well.

Recent studies reported a favorable effect of pregnancy on MS relapse over an early postpartum peak [11]. However, the mechanism is still unknown. In our case, the delirium, as the first presentation of MS, could be provoked from the hormonal changes pre- and postpartum. On the other hand, MRI-confirmed temporal lesions could lead to developing delirium as well.

As a matter of interest, in the therapeutic phase, our patient received $2 \mathrm{~g}$ /day methylprednisolone for 5 days, followed by therapeutic plasma exchange as the therapy of choice for glucocorticosteroid-unresponsive MS patients and an off-label escalation therapy with natalizum$a b$ based on the relatively malignant progression of MS, which to date has caused no complication.

\section{Conclusion}

Detailed physical and extensive neurological examination and appropriate imaging enabled the diagnosis of MS with delirium in this patient, which was followed by the appropriate treatment.

\section{Acknowledgments}

The authors would like to thank Dr. Pgeah Entezari for the language editing and Dr. Nima Mahboobi and Dr. Vahid Tabatabaei for their valuable comments and technical assistance.

\section{References}

1 Rahmlow MR, Cantarci O: Fulminant demyelinating diseases. Neurohospitalist 2013;3: 81-91.

-2 Scolding N: Acute disseminated encephalomyelitis and other inflammatory demyelinating variants. Handb Clin Neurol 2014;122: 601-611.

$>3$ Weinschenker BG, Wingerchuk DM: Neuromyelitis optica: clinical syndrome and the NMO-IgG autoantibody marker. Curr Top Microbiol Immunol 2008;318:343-356.

4 Martins HM, Teixeira AL Jr, Lana-Piexoto MA: Acute hemorrhagic leukoencephalitis mimicking herpes simplex encephalitis. Arq Neuropsiquiatr 2004;62:139-143.
5 Wang JY, Wang K, Chen XW, et al: Meningoencephalitis as an initial manifestation of neuromyelitis optica spectrum disorder. Mult Scler 2013;19:639-643.

6 Karussis D: The diagnosis of multiple sclerosis and the various related demyelinating syndromes: a critical review. J Autoimmun 2014; 48-49:134-142.

7 Messina S, Patti F: Gray matter in multiple sclerosis: cognitive impairment and structural MRI. Mult Scler Int 2014;2014:609694.
8 Tapos D, Sivaswamy L: Mood disorder as the presenting manifestation of demyelination. Case Rep Neurol 2013;5:104-109.

-9 Yadav R, Zigmond AS: Temporal lobe lesions and psychosis in multiple sclerosis. BMJ Case Rep 2010;2010:bcr0120102651.

10 Kosmidis MH, Giannakou M, Messinis L, et al: Psychotic features associated with multiple sclerosis. Int Rev Psychiatry 2010;22:55-66.

11 Hughes SE, Spelman T, Gray OM, et al: Predictors and dynamics of postpartum relapses in women with multiple sclerosis. Mult Scler 2014;20:739-746. 